Article

\title{
Simultaneous Robust Coordinated Damping Control of Power System Stabilizers (PSSs), Static Var Compensator (SVC) and Doubly-Fed Induction Generator Power Oscillation Dampers (DFIG PODs) in Multimachine Power Systems
}

\author{
Jian Zuo *, Yinhong Li, Dongyuan Shi and Xianzhong Duan \\ School of Electrical and Electronic Engineering, State Key Laboratory of Advanced Electromagnetic, \\ Engineering and Technology, Huazhong University of Science and Technology, Wuhan 430074, China; \\ liyinhong@hust.edu.cn (Y.L.); dongyuanshi@hust.edu.cn (D.S.); xzduan@hust.edu.cn (X.D.) \\ * Correspondence: zuojian@hust.edu.cn; Tel.: +86-27-8754-1174
}

Academic Editor: Chunhua Liu

Received: 21 February 2017; Accepted: 15 April 2017; Published: 20 April 2017

\begin{abstract}
The potential of utilizing doubly-fed induction generator (DFIG)-based wind farms to improve power system damping performance and to enhance small signal stability has been proposed by many researchers. However, the simultaneous coordinated tuning of a DFIG power oscillation damper (POD) with other damping controllers is rarely involved. A simultaneous robust coordinated multiple damping controller design strategy for a power system incorporating power system stabilizer (PSS), static var compensator (SVC) POD and DFIG POD is presented in this paper. This coordinated damping control design strategy is addressed as an eigenvalue-based optimization problem to increase the damping ratios of oscillation modes. Both local and inter-area electromechanical oscillation modes are intended in the optimization design process. Wide-area phasor measurement unit (PMU) signals, selected by the joint modal controllability / observability index, are utilized as SVC and DFIG POD feedback modulation signals to suppress inter-area oscillation modes. The robustness of the proposed coordinated design strategy is achieved by simultaneously considering multiple power flow situations and operating conditions. The recently proposed Grey Wolf optimizer (GWO) algorithm is adopted to efficiently optimize the parameter values of multiple damping controllers. The feasibility and effectiveness of the proposed coordinated design strategy are demonstrated through frequency-domain eigenvalue analysis and nonlinear time-domain simulation studies in two modified benchmark test systems. Moreover, the dynamic response simulation results also validate the robustness of the recommended coordinated multiple damping controllers under various system operating conditions.
\end{abstract}

Keywords: coordinated damping control; doubly-fed induction generator (DFIG); static var compensator (SVC); Grey Wolf optimizer (GWO); power oscillation damper (POD)

\section{Introduction}

Sustained power system oscillation has become a serious problem for power system operation and control nowadays. Oscillations cause safety problems in electric power equipment and limit the transmission capacity of long distance power transmission. Even, in the most severe cases, growing power oscillations may lead to the collapse and blackout of the whole interconnected system if no appropriate measures are taken in time [1].

Power system stabilizers (PSSs), as one kind of the most economical and practical devices, have been widely equipped on synchronous generators to provide damping torque and stabilize power 
system oscillations [2], but the damping performance of the conventional PSS in suppressing power system oscillations is limited, especially the inter-area oscillation modes, since the local measurement feedback signals of PSSs are of low inter-area mode observability [3]. To damp out inter-area low frequency oscillation modes more efficiently, new damping measures need to be developed.

Flexible AC transmission system (FACTS) devices, commonly located in power systems, are primarily used for scheduling power flow and/or providing voltage support [4]. Besides that, with the advance of fast acting FACTS controllers, it is possible to improve system dynamic stability and dampen system low frequency oscillations [5]. The concept of power oscillation damper (POD) is widely accepted by the engineers to restrain inter-area oscillations in power grids [6]. Considerable research focus has been given on designing various FACTS PODs and their coordination with PSSs to significantly improve the small signal stability of power systems [7].

On the other hand, due to the energy crisis and environmental pollution problems, generating electricity from clean and renewable energy, especially wind power, has become very popular all around the world $[8,9]$. High proportional integration of wind power generators has an important influence on the dynamic stability of power system [10], while, at the same time, they play a certain role in improving power system stability [11-13]. Recently, several researches have proposed the possibility of using doubly-fed induction generator (DFIG)-based wind farms to improve damping performance and enhance the dynamic stability of wind power integrated power systems [14-21]. Many novel control schemes have been proposed for DFIGs to enable them to provide an auxiliary power system stabilization function or contribute to system voltage support during network faults [20-25]. What is more, wind farm POD design derived from the classical phase compensation principle of PSS has become a research hotspot [23-26]. Many accomplished PSS design methods can be easily applied to design of DFIG POD.

In summary, designing a single type damping controller is already a widely accepted engineering practice. Coordinated control of multiple damping controllers, such as PSSs and PODs, can not only enhance system dynamic stability but also increase system operating flexibility. However, when PSS, FACTS and DFIG exist in a system, how to realize coordinated tuning of multiple damping controllers is a challenging problem. This paper is dedicated to develop an alternative coordinated scheme for multiple damping controllers and discuss the theoretical feasibility. To obtain the most effective signal (with global observability) to achieve a more efficient inter-area damping control, remote signal measured by phasor measurement unit (PMU) and transmitted by wide-area measurement system (WAMS) network should be input to POD. The potential of coordinated control of local conventional PSSs and PMU-based novel wide-area controller, for instance, SVC POD or DFIG-based wind farm POD, is able to simultaneously suppress both local and inter-area low frequency oscillations. The literature survey [27] summarizes that there are considerable researches on damping control by a single type damping controller in power system integrated with wind power generation, whereas less attention has been paid for coordinated tuning of multiple damping controllers, especially in a wide-area measurement scenario. Reference [28] presents a new two-level hierarchical wide-area control strategy, which contains a variable speed permanent magnet synchronous motor (PMSG)-based wind farm and a static synchronous compensator (STATCOM), to provide frequency support and inter-area oscillation damping capability. An optimization-based sequential design strategy is proposed in [29] to coordinate multiple local PSSs and one wide-area high voltage direct current (HVDC) stabilizer, and the overall system stability is greatly enhanced. Reference [30] presents a genetic algorithm-based damping control parameters turning methods of DFIG type wind generators, the system damping is improved under various wind speed conditions. The coordinated control of DFIG POD and local PSSs to damp power system oscillations is investigated in [31], and the parameter optimization problem of the damping controllers considering system uncertainties is solved by an improved firefly algorithm.

A simultaneous robust coordinated multiple damping controllers design strategy is presented in this paper to suppress local and inter-area low frequency oscillation modes and enhance power 
system dynamic stability through simultaneously optimizing multiple local PSSs and wide-area signal based SVC device and wind farm additional PODs. A classical lead-lag type POD is adopted in this coordinated design strategy. The joint modal controllability/observability index is employed to choose the most appropriate wide-area feedback signals for PODs [32]. The coordinated design strategy is addressed as an eigenvalue-based optimization problem [33]. The recently proposed Grey Wolf optimizer (GWO) algorithm is used to optimize the optimum parameter values of damping controllers.

This paper is organized as follows: the mathematical models for the studied power system integrated with SVC, wind farm and its controllers, including PSS and POD, are introduced first. Then, the selection method of the best wide-area feedback signals for each POD, the eigenvalue-based optimization problem, the GWO algorithm, and the parameter optimization design procedure for the coordinated multiple damping controllers are depicted. Moreover, the linear modal analysis and nonlinear time-domain dynamic simulation of two modified benchmark test systems with and without the optimized coordinated damping controllers under a variety of scenarios are demonstrated later. Finally, the conclusions are given.

\section{Mathematical Modeling}

The modelling of power system dynamic devices with their controllers, including exciter, SVC and wind turbine used in this study, for the coordinated optimization of the proposed control strategy, is given as below.

\subsection{AVR with PSS Model}

Figure 1 depicts a simple automatic voltage regulator (AVR) with PSS, the dynamic behavior of AVR is described as follow:

$$
E_{f d}=\frac{K_{A}\left(V_{r e f}-v+u_{P S S}\right)}{\left(1+s T_{A}\right)}
$$

where $E_{f d}$ and $V_{\text {ref }}$ are the output voltage and reference voltage of AVR, $v$ is the principal input signal of excitation system; $u_{P S S}$ is the output stabilizing signal of PSS, $K_{A}$ and $T_{A}$ are the exciter gain and time constant.

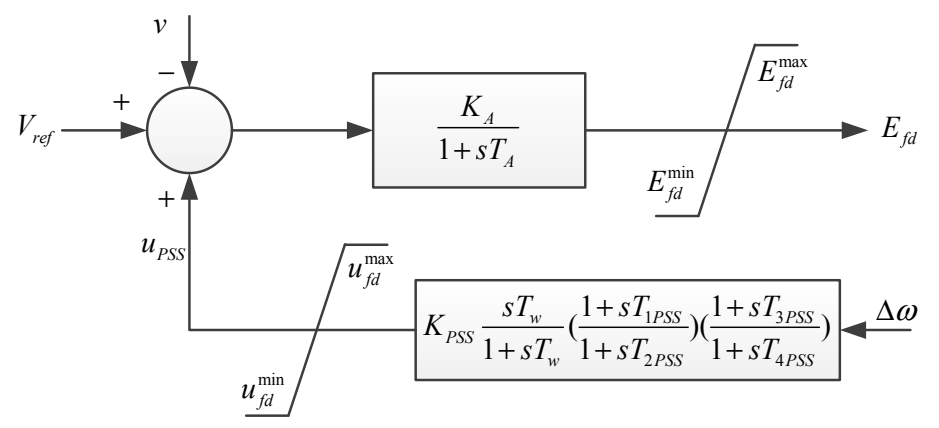

Figure 1. A simple automatic voltage regulator (AVR) with fixed-structure lead-lag type power system stabilizer (PSS).

As shown in Figure 1, a common lead-lag type PSS is used in this study [34]. The main purpose of PSS is to increase damping torque and suppress oscillations between synchronous machines through modulating the input voltage of the excitation system [2]. The dynamic model of a PSS is mathematically described by:

$$
u_{P S S}=K_{P S S} \frac{s T_{\omega}}{1+s T_{\omega}}\left(\frac{1+s T_{1 P S S}}{1+s T_{2 P S S}}\right)\left(\frac{1+s T_{3 P S S}}{1+s T_{4 P S S}}\right) \cdot \Delta \omega
$$

where the PSS gain $K_{P S S}$ and corresponding lead-lag time constants $T_{1 P S S}, T_{2 P S S}, T_{3 P S S}, T_{4 P S S}$ can be tuned by various methods. $T_{\omega}$ is the washout time constant, usually selected to be $5 \mathrm{~s}$ or $10 \mathrm{~s}$. 


\subsection{SVC with POD Model}

In a power system, various types of FACTS devices are installed dispersedly. The main purpose of FACTS is to control system power flow, improve voltage level, compensate reactive power and enhance stability. The most commonly used parallel type FACTS, named SVC, is adopted in this work to provide voltage support for weak bus in the test system [4]. An SVC is composed of a controllable reactance and fixed capacitors. The dynamic regulator model of SVC, as depicted in Figure 2, can be described as follows [35]:

$$
\dot{b}_{S V C}=\frac{K_{r}\left(v_{0}^{r e f}+v_{s}^{P O D}-v\right)-b_{S V C}}{T_{r}}
$$

where $b_{S V C}$ is the reactance of SVC, $K_{r}$ and $T_{r}$ are the gain and time constant of SVC regulator, $v, v_{0}^{r e f}$ and $v_{s}^{P O D}$ are system bus voltage, initial reference voltage and additional POD output modulating signal of SVC, respectively. At the SVC bus, the injection of reactive power is:

$$
Q_{S V C}=b_{S V C} \cdot v^{2}
$$

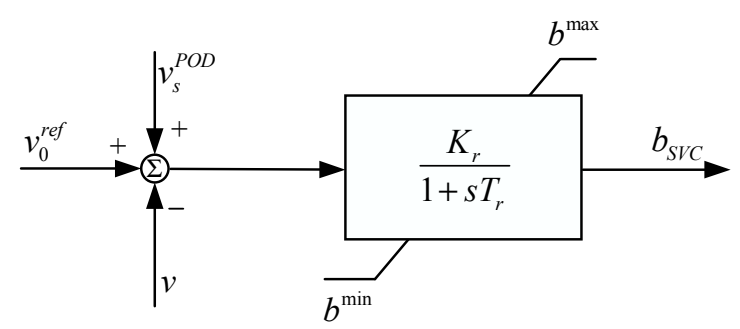

Figure 2. Static var compensator (SVC) regulator structure.

In addition to the voltage regulation role, a supplementary wide-area POD output modulating signal is input to the voltage control loop of SVC device to provide additional damping torque effect for electromechanical oscillations. As shown in Figure 3, the structure of SVC POD is almost the same as PSS. The POD is usually composed of a stabilizer gain $K_{S t a b}$, a washout stage $T_{\omega}$, and a 2nd lead-lag stage with time constants $T_{1 P O D}, T_{2 P O D}, T_{3 P O D}$, and $T_{4 P O D}$. The input signal is the wide-area signal which can ensure inter-area mode observability, while the output signal $v_{s}^{P O D}$ is used to adjust SVC reactive power injection. An anti-windup limiter with minimum and maximum of $\Delta u_{P O D}$ ( \pm 0.1 p.u.) limits a too large output of POD. The amount of damping introduced by POD is determined by the stabilizer gain $K_{\text {Stab }}$ while the phase compensation of the damping signal is adjusted by the 2 nd lead-lag compensator stage.

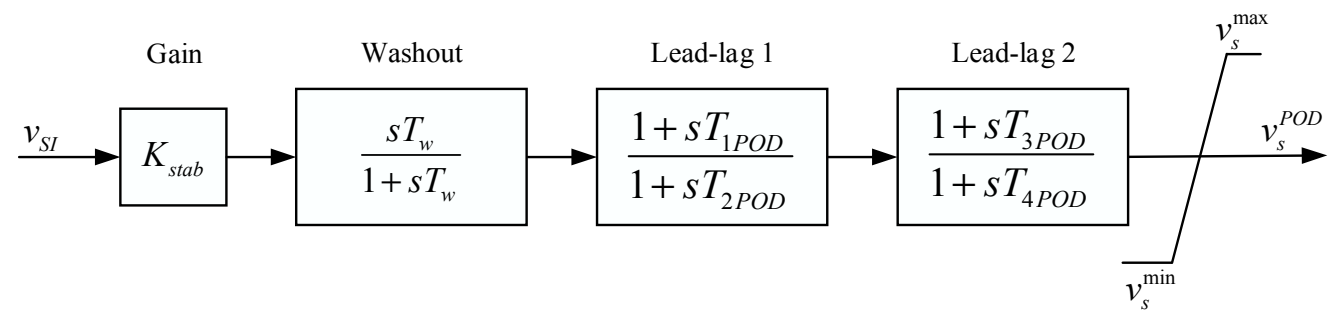

Figure 3. The structure of static var compensator power oscillation damper (SVC POD).

\subsection{DFIG-Based Wind Farm with POD Model}

To simplify the modeling, a wind farm composed of multiple parallel DFIG-based wind turbines usually can be equivalent to a single aggregated wind power plant. Since we mainly focus on the electromechanical dynamic behavior of wind generators, the dynamic model of DFIG-based wind 
turbine depicted in Figure 4 is adopted in this study [35]. The algebraic relations of the DFIG's electrical equations are described as follows.

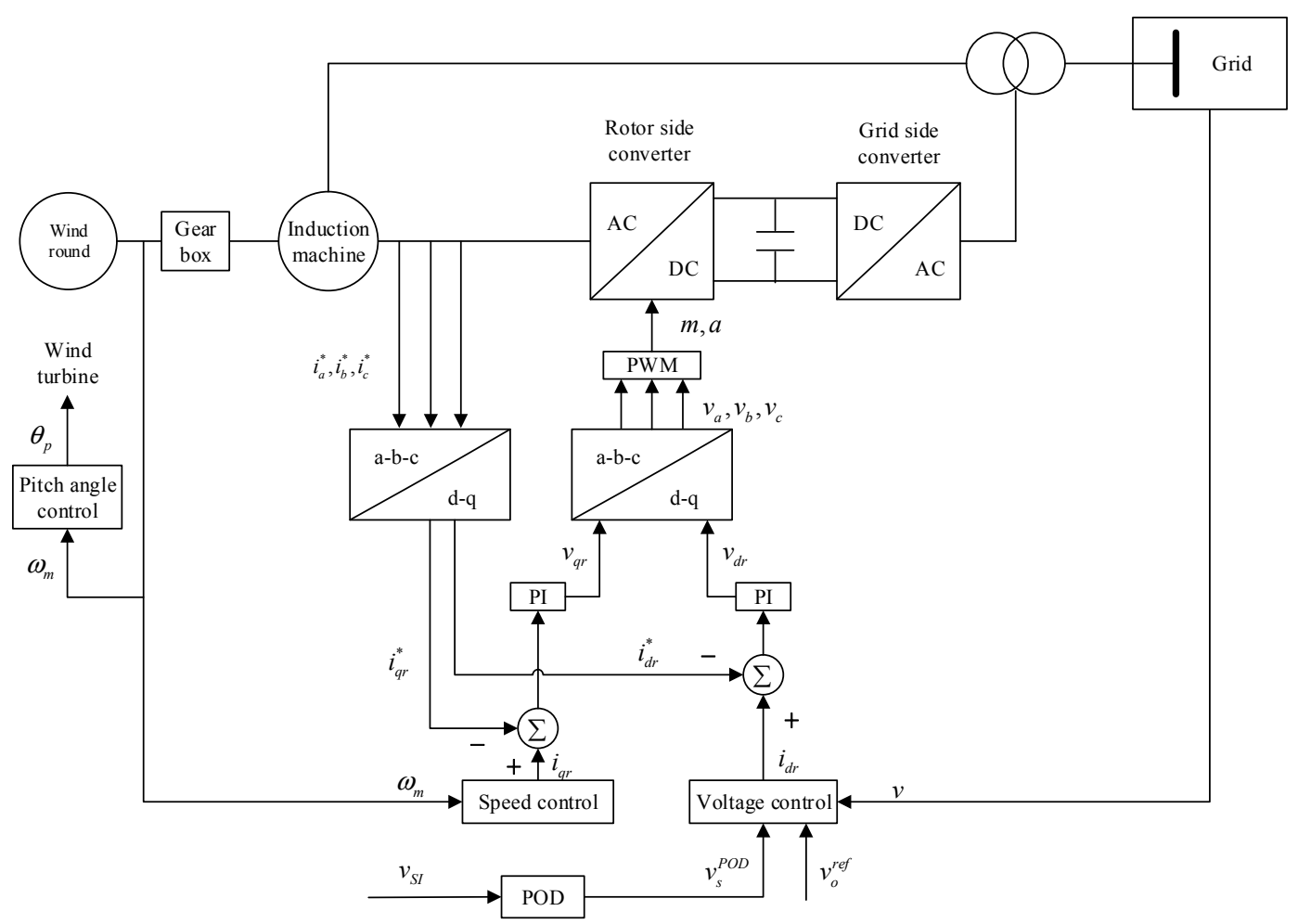

Figure 4. The structure of the doubly-fed induction generator (DFIG) and vector control strategy.

$$
\begin{aligned}
& v_{d s}=-r_{s} i_{d s}+\left(\left(x_{s}+x_{\mu}\right) i_{q s}+x_{\mu} i_{q r}\right) \\
& v_{q s}=-r_{s} i_{q s}-\left(\left(x_{s}+x_{\mu}\right) i_{d s}+x_{\mu} i_{d r}\right) \\
& v_{d r}=-r_{r} i_{d r}+\left(1-\omega_{m}\right)\left(\left(x_{s}+x_{\mu}\right) i_{q r}+x_{\mu} i_{q s}\right) \\
& v_{q r}=-r_{r} i_{q r}-\left(1-\omega_{m}\right)\left(\left(x_{s}+x_{\mu}\right) i_{d r}+x_{\mu} i_{d s}\right)
\end{aligned}
$$

where $v_{d s}, v_{q s}, v_{d r}$, and $v_{q r}$ are the stator and rotor voltages of $d$ and $q$ axis, $i_{d s}, i_{q s}, i_{d r}$, and $i_{q r}$ are the stator and rotor currents $\mathrm{d}$ and $\mathrm{q}$ axis, $r_{s}$ and $r_{r}$ are the stator and rotor resistances, $x_{s}$ and $x_{\mu}$ are the stator self and magnetizing reactance, and $\omega_{m}$ is wind turbine rotor speed.

The $d$ and $q$ stator voltage are calculated by:

$$
\begin{aligned}
& v_{d s}=-v \sin \theta \\
& v_{q s}=v \cos \theta
\end{aligned}
$$

The wind generator output powers $P$ and $Q$ are described as:

$$
\begin{aligned}
& P=v_{d s} i_{d s}+v_{q s} i_{q s}+v_{d c} i_{d c}+v_{q c} i_{q c} \\
& Q=v_{q s} i_{d s}-v_{d s} i_{q s}+v_{q c} i_{d c}-v_{d c} i_{q c}
\end{aligned}
$$

where $v_{d c}, v_{q c}, i_{d c}$ and $i_{q c}$ are the converter voltages and currents of $d$ and $q$ axis, respectively. On the grid side, the converter powers $P_{c}$ and $Q_{c}$ are:

$$
\begin{aligned}
& P_{c}=v_{d c} i_{d c}+v_{q c} i_{q c} \\
& Q_{c}=v_{q c} i_{d c}-v_{d c} i_{q c}
\end{aligned}
$$


Whereas, on the rotor side, the converter powers $P_{r}$ and $Q_{r}$ are:

$$
\begin{aligned}
& P_{r}=v_{d r} i_{d r}+v_{q r} i_{q r} \\
& Q_{r}=v_{q r} i_{d r}-v_{d r} i_{q r}
\end{aligned}
$$

With the assumption of ideal converter model, it can be obtained that $P_{c}=P_{r}$. The powers injected into the grid are:

$$
\begin{aligned}
& P=v_{d s} i_{d s}+v_{q s} i_{q s}+v_{d r} i_{d r}+v_{q r} i_{q r} \\
& Q=-\frac{x_{\mu} v i_{d r}}{x_{s}+x_{\mu}}-\frac{v^{2}}{x_{\mu}}
\end{aligned}
$$

The DFIG rotor motion equation is expressed by:

$$
\begin{aligned}
& \dot{\omega}_{m}=\frac{\tau_{m}-\tau_{e}}{2 H_{m}} \\
& \tau_{e}=\psi_{d s} i_{q s}-\psi_{q s} i_{d s} \\
& \tau_{m}=\frac{P_{w}}{\omega_{m}}
\end{aligned}
$$

where $H_{m}$ is wind turbine rotor inertia, $P_{w}$ is the mechanical power, $\tau_{m}$ and $\tau_{e}$ are mechanical and electrical torques, and $\psi_{d s}$ and $\psi_{q s}$ are the stator fluxes of $d$ and $q$ axis. The relationship between stator fluxes and generator currents is:

$$
\begin{aligned}
& \psi_{d s}=-\left(\left(x_{s}+x_{\mu}\right) i_{d s}+x_{\mu} i_{d r}\right) \\
& \psi_{q s}=-\left(\left(x_{s}+x_{\mu}\right) i_{q s}+x_{\mu} i_{q r}\right)
\end{aligned}
$$

Therefore, the electrical torque $\tau_{e}$ is described as:

$$
\tau_{e}=x_{\mu}\left(i_{q r} i_{d s}-i_{d r} i_{q s}\right)
$$

and it is approximated as:

$$
\tau_{e}=-\frac{x_{u} v i_{q r}}{\omega_{b}\left(x_{s}+x_{u}\right)}
$$

where $\omega_{b}$ is the system frequency.

For detailed dynamic models of rotor speed control, voltage control, and pitch angle control, please refer to [35]. The dynamic equations as well as the control structure of wide-area signal based DFIG POD are the same as the SVC POD. The input wide-area signal of DFIG POD is the line active power measured by $P M U$, and the output signal $v_{s}^{P O D}$ is used to modulate the voltage control loop of DFIG.

\subsection{Linearized Power System Dynamic Model}

A multimachine power system dynamic is mathematically represented as follow:

$$
\begin{aligned}
& \dot{x}=f(x, y, u) \\
& 0=g(x, y, u) \\
& z=h(x, y, u)
\end{aligned}
$$

where $f(x, y, u)$ is the differential equations of dynamic components, $g(x, y, u)$ is the network algebraic equations, $\boldsymbol{h}(\boldsymbol{x}, \boldsymbol{y}, \boldsymbol{u})$ is the output equations. $\boldsymbol{x}$ is the state variable, $\boldsymbol{y}$ is the algebraic variable, $\boldsymbol{u}$ is the input variable, and $z$ is the system output variable.

After solving the network power flow solution, the linearized state-space equations of (15) are formulated as:

$$
\begin{aligned}
& \dot{x}=\mathrm{A} x+\mathrm{B} u \\
& z=\mathrm{C} x+\mathrm{D} u
\end{aligned}
$$


where the incremental symbol $\Delta$ is omitted, $\mathbf{A}$ is the system state matrix, $\mathbf{B}$ is the input matrix, $\mathbf{C}$ is the output matrix and $\mathbf{D}$ is the feedforward matrix. This state-space Equation (16) is used for power system modal analysis and damping controller design. From the stability theory of Liapunov's indirect method, the eigenvalues of linear system state matrix $\mathbf{A}$ reveals the equilibrium point asymptotic stability of the studied dynamic power system.

\section{Proposed Simultaneous Robust Coordinated Damping Control Design}

\subsection{Selection of the Wide-Area Feedback Signals}

In general, inter-area oscillation modes cannot be well suppressed by local feedback signal-based damping controller. That is because inter-area oscillation modes are usually globally observable. GPS-based WAMS, composed by multiple dispersed PMUs and central phasor data concentrators (PDCs), is used to preferably understand and control the increasingly complex dynamic behaviors exhibited by large-scale power systems [3]. The selection of appropriate feedback signals for PODs plays an important role in not only designing an effective damping controller but also coordinating multiple wide-area damping controllers. The principle of selecting wide-area POD feedback signals is to achieve a superior damping effect on the concerned electromechanical oscillation modes and try not to affect other oscillation modes. A plenty of research has demonstrated the theoretical validity and practical availability of geometric and residue approaches to choose the most suitable wide-area feedback signal for POD [36-38]. In this study, the concept of joint modal controllability/observability index is adopted as wide-area feedback signals selection method to decouple modal interactions of multiple feedback signals [32].

Based on the modal analysis theory, the modal controllability index $\left(\mathrm{COI}_{j}\right)$ and observability index $\left(O B I_{k}\right)$ of the $i$ th oscillation mode is expressed as:

$$
\begin{gathered}
\operatorname{COI}_{j}(i)=\cos \left(\delta\left(\Psi_{i}, \mathbf{B}_{j}\right)\right)=\frac{\left|\mathbf{B}_{j}^{T} \mathbf{\Psi}_{i}\right|}{\left\|\mathbf{B}_{j}\right\|\left\|\mathbf{\Psi}_{i}\right\|} \\
O B I_{k}(i)=\cos \left(\delta\left(\boldsymbol{\Phi}_{i}, \mathbf{C}_{k}\right)\right)=\frac{\left|\mathbf{C}_{k} \boldsymbol{\Phi}_{i}\right|}{\left\|\mathbf{C}_{k}\right\|\left\|\boldsymbol{\Phi}_{i}\right\|}
\end{gathered}
$$

where $\mathbf{B}_{j}$ is the $j$ th column of input matrix $\mathbf{B}$ and $\mathbf{C}_{k}$ is the $k$ th row of output matrix C. $\delta\left(\mathbf{\Psi}_{i}, \mathbf{B}_{j}\right)$ is the angle of the input vector $\mathbf{B}_{j}$ and the right eigenvector $\boldsymbol{\Psi}_{i}$, and $\delta\left(\boldsymbol{\Phi}_{i}, \mathbf{C}_{k}\right)$ is the angle of the output vector $\mathbf{C}_{k}$ and the left eigenvector $\boldsymbol{\Phi}_{i}$.

Then, the joint modal controllability/observability index $C O B I_{i}(j, k)$ is expressed by:

$$
\operatorname{COBI}_{i}(j, k)=\mathrm{COI}_{j}(i) \cdot \mathrm{OBI}_{k}(i)
$$

where $\mathrm{COI}_{j}(i)$ indicates the controllability of the $j$ th actuator (generator or FACTS) for stabilization of the ith oscillation mode $\left(\lambda_{i}\right) ; O B I_{k}(i)$ indicates the observability of the $k$ th input signal (local or remote) for observation of the $i$ th oscillation mode $\left(\lambda_{i}\right)$.

For a power system with multiple wide-area controllers, the wide-area signal of each controller can be obtained through finding the corresponding signal with maximum COBI index. In case that the signal with maximum $C O B I$ index cannot be accessed, such as remote signal which cannot be measured by PMU, the subprime indicators of $C O B I$ index for POD signal can be considered. A relatively optimal damping performance can also be obtained.

\subsection{Formulation of the Optimization Problem}

The fundamental purpose of the coordinated multiple damping controllers design strategy is to improve overall power system oscillation stability by the supplementary damping controllers. To maximize damping performance of overall multimachine power systems, an eigenvalue-based 
objective with maximization of damping ratios is taken into consideration in this paper. Thus, the objective function $J$ is given to be:

$$
\text { Minimize } \quad J=\sum_{j=1}^{n p} \sum_{\zeta_{i, j}<\zeta_{0}}\left(\zeta_{0}-\zeta_{i, j}\right)^{2}
$$

where $n p$ is the system operation scenario number considered in the PSSs and PODs parameter optimization tuning process. $\zeta_{0}$ is the expected minimum damping ratio, and $\zeta_{i j}$ is the $i$ th damping ratio of oscillation mode eigenvalue corresponding to the $j$ th operating condition. The damping ratio $\zeta_{i j}<\zeta_{0}$ is considered in the optimization objective function $J$, and the minimization of $J$ will move the eigenvalues to the specified sector region in left half $s$-plane with damping ratio $\zeta_{i j}>\zeta_{0}$, as shown in Figure 5.

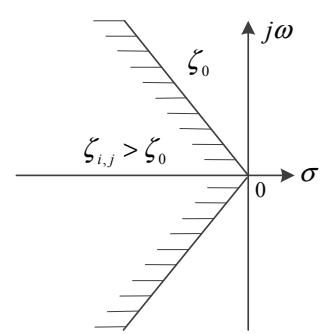

Figure 5. The specified sector region in left half s-plane.

The optimization constraints are the bounds of the optimized parameters such as stabilizer gain $K$ (including $K_{P S S}$ and $K_{S t a b}$ ) and the time constants $T_{1,2,3,4}$ (including $T_{1 P S S}, T_{2 P S S}, T_{3 P S S}, T_{4 P S S}, T_{1 P O D}$, $T_{2 P O D}, T_{3 P O D}$, and $T_{4 P O D}$, where $\left.T_{1}=T_{3}, T_{2}=T_{4}\right)$. Therefore, the optimization process is expressed as minimizing $J$ subject to:

$$
\begin{aligned}
& K^{\min } \leq K \leq K^{\max } \\
& T_{1,3}^{\min } \leq T_{1,3} \leq T_{1,3}^{\max } \\
& T_{2,4}^{\min } \leq T_{2,4} \leq T_{2,4}^{\max }
\end{aligned}
$$

The upper and lower bounds are $[0.1,50]$ for $K,[0.01,1.0]$ for $T_{1,3}$ and $[0.01,0.1]$ for $T_{2,4}$. The typical time constants $T_{w}$ is considered as $10 \mathrm{~s}$ as in [39].

\subsection{Application of GWO Algorithm}

GWO algorithm, invented as an optimization tool by Mirjalili et al. [40] in 2014, is a high searching performance heuristic algorithm. It imitates the hunting behaviour of grey wolves and utilizes the leadership hierarchy of wolf pack [40]. This algorithm is adopted here for searching the appropriate parameters of multiple damping controllers.

A typical feature of the grey wolves is that a strict social dominant hierarchy relationship exists in different individuals of grey wolves. And the grey wolves can be divided into four hierarchies. They are called $\alpha, \beta, \delta$, and $\omega$, whose dominance decreases in turn. The hunting is led by $\alpha, \beta$, and $\delta$, which means, these three kinds of wolves guide the $\omega$ wolves in the optimization process of GWO algorithm.

Besides the social organization hierarchy of grey wolf pack, the hunting behaviour is mathematically modeled to implement GWO and perform optimization. The hunting behaviours of grey wolves mainly include three stages: (i) Tracking the prey; (ii) Encircling the prey; and (iii) Attacking the prey. The hunting behaviours mainly used for modelling GWO algorithm are described as following. 
- Encircling prey

The encircling behaviour of prey can be described as following equations:

$$
\begin{aligned}
& \vec{D}=\left|\vec{C} \cdot \vec{X}_{p}(t)-\vec{X}\right| \\
& \vec{X}(t+1)=\vec{X}_{p}(t)-\vec{A} \cdot \vec{D} \\
& \vec{A}=2 \vec{a} \cdot \vec{r}_{1}-\vec{a} \\
& \vec{C}=2 \cdot \vec{r}_{2}
\end{aligned}
$$

where $t$ denotes the current generation, $\vec{X}_{p}$ and $\vec{X}$ indicate the positions of the prey and a grey wolf, $\vec{A}$ and $\vec{C}$ are coefficients and can be calculated as (22), $\vec{a}$ is linearly decreasing from 2.0 to 0 during the iterative process of the optimization, $\vec{r}_{1}$ and $\vec{r}_{2}$ are two random vectors between 0 and 1 .

- Hunting prey

In the hunting process, it assumes that the $\alpha, \beta$, and $\delta$ wolves have better information about the location of the prey. Therefore, the best three solutions obtained in the current generation are used to guide the $\omega$ wolves and update their positions. The mathematical formulation of the grey wolves' hunting behavior is described as follows:

$$
\begin{aligned}
& \vec{D}_{\alpha}=\left|\begin{array}{l}
\vec{C}_{1} \cdot \vec{X}_{\alpha}-\vec{X} \\
\vec{D}_{\beta} \cdot \vec{X}_{\beta}-\vec{X}
\end{array}\right| \\
& \vec{D}_{\delta}=\left|\vec{C}_{3} \cdot \vec{X}_{\delta}-\vec{X}\right| \\
& \vec{X}_{1}=\vec{X}_{\alpha}-\vec{A}_{1} \cdot\left(\vec{D}_{\alpha}\right) \\
& \vec{X}_{2}=\vec{X}_{\beta}-\vec{A}_{2} \cdot\left(\vec{D}_{\beta}\right) \\
& \vec{X}_{3}=\vec{X}_{\delta}-\vec{A}_{3} \cdot\left(\vec{D}_{\delta}\right) \\
& \vec{X}(t+1)=\left(\vec{X}_{1}+\vec{X}_{2}+\vec{X}_{3}\right) / 3
\end{aligned}
$$

- Attacking prey

Grey wolves attack the prey and finish the hunting process when they stop moving. The value of $\vec{a}$ gradually decreases from 2.0 to 0 to formulize the approaching of the prey. While the fluctuating region of the randomized $\mathbf{A}$ in $[-2 a, 2 a]$ is also decreased by $a$. When the values of $\vec{A}$ are in the range of $[-1,1]$ (which is $\vec{A}<1$ ), then, the next position of a grey wolf can be at any possible position between itself and the prey. The operators of hunting and attacking may lead to the GWO algorithm easily falling into local minimum. Although the proposed encircling mechanism of GWO shows exploration to some extent, it needs more operators to enhance the ability of exploration.

- Searching for prey

Grey wolves mainly find their prey according to the current position of the $\alpha, \beta, \delta$, and $\omega$ wolves. They go away from each other to search a proper prey. Finally, the wolves attack the prey and converge to it. The random values $|\vec{A}|>1$ indicate that the grey wolf is to deviate from the prey. The operator of searching is to emphasize the global search ability of GWO and achieve the global optimal solution efficiently. The main flow chart of the suggested GWO algorithm for tuning the parameters of multiple PSSs and PODs is presented in Figure 6. 


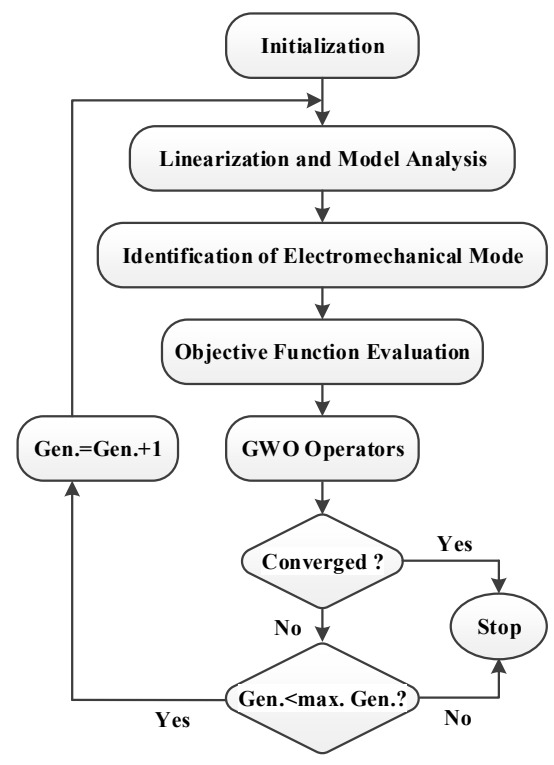

Figure 6. The flow chart of suggested GWO algorithm for tuning parameters of PSSs and PODs.

\section{Case Study of Two-area Kundur Test System}

To verify the feasibility and effectiveness of the presented coordinated multiple damping controllers design strategy and optimization algorithm, a comprehensive case study is implemented on a modified classical two-area Kundur test system. Firstly, there is no PSS and POD controller equipped in the system. Secondly, only local PSS is used to improve oscillation mode damping. Thirdly, supplementary controllers (PODs) of SVC and DFIG are adopted. The proposed coordinated design strategy enables local PSSs to cooperate with wide-area PODs to damp out local and inter-area electromechanical oscillations.

PSAT 2.1.8 and Matlab 2014a programs are employed in this study to perform the optimization process of damping controller parameter design, system eigenvalue analysis, as well as dynamic time-domain simulation [41]. The initial parameter settings of GWO algorithm are: the number of search agents is 50 , the number of iterations is 100 , the dimensionality of search variables depends on the number of controllers (PSSs and PODs), while each controller corresponds to three search variables.

\subsection{Study System}

A system single line diagram shown in Figure 7 is modified from the classical two-area Kundur test system, which is a classically used study system for small signal stability analysis and damping control design of power system. In this approximate symmetrical system, not only local but also inter-area oscillation modes can be distinctly observed. The original data of the network and synchronous generators can be found in [34]. All of the four generators are described by 6-order dynamic models and IEEE Type-ST1 simple static excitation system are installed. WG represents a $100 \mathrm{MW}$ (or 50 with $2 \mathrm{MW}$ each) DFIG based wind farm and is integrated into the system at bus 6 of area 1. A 200 MVar SVC equipped at the middle of the interconnection line 7-9 is utilized to enhance the system voltage stability, and meanwhile, improve the power transmission capacity.

To verify the superiority of the proposed coordinated design strategy, four scenarios are assumed as follows:

(1) The test system without PSS and POD;

(2) The test system with PSSs only;

(3) The test system with PSSs and SVC POD;

(4) The test system with PSSs, SVC and DFIG POD. 
To strengthen the robustness of the proposed coordinated design strategy, three power flow operating conditions are considered during the optimization procedure. The active power transfer from area 1 to 2 are about 380, 480 and $580 \mathrm{MW}$, representing the light, normal and heavy inter-area power flow transmission condition, respectively.

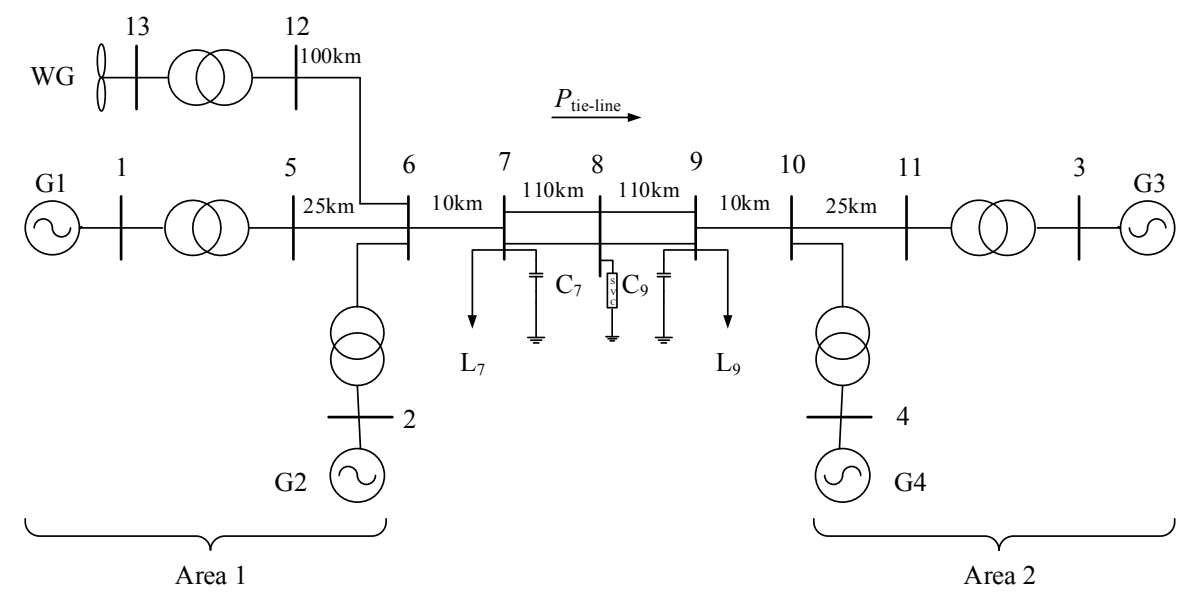

Figure 7. Modified Two-area Kundur test system.

\subsection{Eigenvalue Analysis without Controllers and with PSSs Only}

Eigenvalue analysis under three transmission power levels of the tie lines reveals that the studied system is unstable if there is no damping controller. As listed in Table 1, there are four electromechanical oscillation modes, including two local oscillation modes with low damping ratio, one unstable/critical stable inter-area oscillation mode (Mode 3 is in bold font in the table), and one additional poorly damped global oscillation mode corresponding to DFIG wind farm and all of the synchronous generators. It can be discovered that the integration of DFIG-based wind farm in power system introduces an additional underdamped oscillation mode M4.

Table 1. The oscillation modes without PSS and POD.

\begin{tabular}{|c|c|c|c|c|c|}
\hline Case & Mode & Eigenvalue & Frequency $(\mathrm{Hz})$ & Damping & Participation Generator \\
\hline \multirow{4}{*}{$\begin{array}{l}380 \mathrm{M} \text { light } \\
\text { power }\end{array}$} & M 1 & $-0.783 \pm j 6.93$ & 1.11 & 11.2 & G1, G2 \\
\hline & M 2 & $-0.893 \pm j 7.11$ & 1.14 & 12.5 & G3, G4 \\
\hline & M3 & $-0.005 \pm \mathrm{j} 4.02$ & 0.639 & 0.12 & All G \\
\hline & M 4 & $-0.014 \pm \mathrm{j} 0.77$ & 0.123 & 1.82 & WG \& G \\
\hline \multirow{4}{*}{$\begin{array}{l}480 \text { M normal } \\
\text { power }\end{array}$} & M 1 & $-0.782 \pm j 6.93$ & 1.11 & 11.2 & G1, G2 \\
\hline & M 2 & $-0.890 \pm j 7.10$ & 1.14 & 12.4 & G3, G4 \\
\hline & M3 & $0.0011 \pm \mathrm{j} 3.98$ & 0.633 & -0.03 & All G \\
\hline & M 4 & $-0.018 \pm j 0.85$ & 0.135 & 2.12 & WG \& G \\
\hline \multirow{4}{*}{$\begin{array}{l}580 \mathrm{M} \text { heavy } \\
\text { power }\end{array}$} & M 1 & $-0.781 \pm j 6.92$ & 1.11 & 11.2 & G1, G2 \\
\hline & M 2 & $-0.890 \pm j 7.08$ & 1.14 & 12.6 & G3, G4 \\
\hline & M3 & $0.0088 \pm j 3.87$ & 0.616 & -0.23 & All G \\
\hline & M 4 & $-0.028 \pm j 0.96$ & 0.153 & 2.91 & WG \& G \\
\hline
\end{tabular}

When the system undertaken is only equipped with two local generator rotor speed feedback PSSs at G1 and G3 and without any wide-area POD, the results of the electromechanical oscillation modes obtained by modal analysis are listed in Table 2. Obviously, all of the four oscillation modes' damping ratios are improved, and the damping ratios of two local modes are larger than $20 \%$ under all of the three operating conditions, so the local mode oscillations can be well damped by two PSSs. However, the critical inter-area oscillation mode $\mathrm{M} 3$ (bold in the table) is still low damping ( $\zeta_{\mathrm{M} 3} \approx 7.5 \%$ ) under all of the three operating conditions. The damping ratios do not meet the expected requirements of $20 \%$. 
Table 2. The oscillation modes with PSSs only.

\begin{tabular}{|c|c|c|c|c|c|}
\hline Case & Mode & Eigenvalue & Frequency $(\mathrm{Hz})$ & Damping & Participation Generator \\
\hline \multirow{4}{*}{$\begin{array}{l}380 \mathrm{M} \text { light } \\
\text { power }\end{array}$} & M1 & $-1.638 \pm j 7.45$ & 1.21 & 21.4 & G1, G2 \\
\hline & M 2 & $-1.773 \pm j 7.70$ & 1.26 & 22.5 & G3, G4 \\
\hline & M3 & $-0.311 \pm \mathrm{j} 4.07$ & 0.650 & 7.62 & All G \\
\hline & M 4 & $-0.202 \pm j 0.76$ & 0.125 & 25.7 & WG \& G \\
\hline \multirow{4}{*}{$\begin{array}{l}480 \mathrm{M} \text { normal } \\
\text { power }\end{array}$} & M1 & $-1.639 \pm j 7.44$ & 1.21 & 21.5 & G1, G2 \\
\hline & M 2 & $-1.768 \pm j 7.67$ & 1.25 & 22.5 & G3, G4 \\
\hline & M3 & $-0.303 \pm \mathrm{j} 4.02$ & 0.642 & 7.52 & All G \\
\hline & M 4 & $-0.205 \pm j 0.83$ & 0.136 & 23.9 & WG \& G \\
\hline \multirow{4}{*}{$\begin{array}{l}580 \mathrm{M} \text { heavy } \\
\text { power }\end{array}$} & M 1 & $-1.641 \pm j 7.42$ & 1.20 & 21.6 & G1, G2 \\
\hline & M 2 & $-1.769 \pm j 7.64$ & 1.25 & 22.7 & G3, G4 \\
\hline & M3 & $-0.286 \pm j 3.90$ & 0.622 & 7.31 & All G \\
\hline & M 4 & $-0.229 \pm j 0.94$ & 0.154 & 23.7 & WG \& G \\
\hline
\end{tabular}

\subsection{Eigenvalue Analysis with PSSs and SVC POD}

When SVC POD is considered in this system, the suitable input remote signal needs to be selected first. Modal analysis is applied to the linearized two-area test system to obtain the geometric measures of $C O B I$. The COBI results with respect to SVC of all lines' active powers for two inter-area oscillation modes are shown in Figure 8. We can see from the histogram in Figure 8 and find that the active power in line 8-9 has the highest observability of both two inter-area modes, therefore, the best wide-area feedback input signal for SVC POD is the active power in line 8-9.

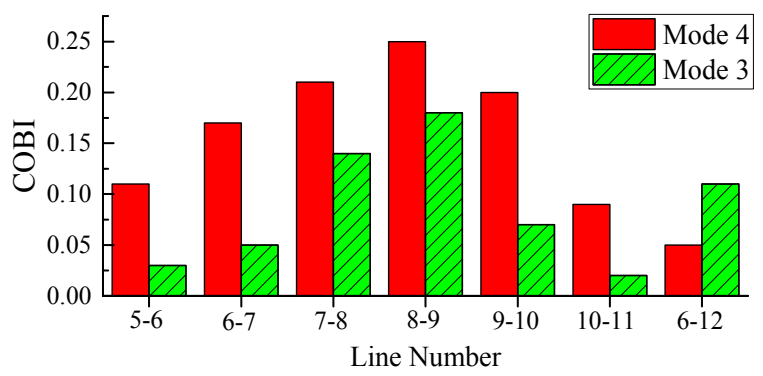

Figure 8. The joint modal controllability / observability index (COBI) of line active power as the input feedback signal of SVC POD.

The GWO algorithm proposed in Section 3.3 is adopted to realize a coordinated tuning of PSSs and SVC POD parameters. The dimension of the optimization problem is 9 for two PSSs and one SVC POD. After the optimization process, the parameters are obtained and listed in Table 3. As the modal analysis results shown in Table 4, all of the four oscillation modes' damping ratios are increased by the coordinated PSSs and SVC POD, especially, those of the two inter-area oscillation modes.

Table 3. Optimized parameters of PSSs and SVC POD.

\begin{tabular}{cccc}
\hline Stabilizer & $K$ & $\boldsymbol{T}_{\mathbf{1}}, \boldsymbol{T}_{\mathbf{3}}$ & $\boldsymbol{T}_{\mathbf{2}}, \boldsymbol{T}_{\mathbf{4}}$ \\
\hline PSS1 & 18.4 & 0.966 & 0.046 \\
PSS3 & 21.6 & 0.593 & 0.083 \\
SVC POD & 16.8 & 0.627 & 0.056 \\
\hline
\end{tabular}


Table 4. The oscillation modes with PSSs and SVC POD.

\begin{tabular}{|c|c|c|c|c|c|}
\hline Case & Mode & Eigenvalue & Frequency $(\mathrm{Hz})$ & Damping & Participation Generator \\
\hline \multirow{4}{*}{$\begin{array}{l}380 \mathrm{M} \text { light } \\
\text { power }\end{array}$} & M 1 & $-2.681 \pm j 8.51$ & 1.42 & 30.1 & G1, G2 \\
\hline & M 2 & $-2.858 \pm j 9.00$ & 1.50 & 30.3 & G3, G4 \\
\hline & M 3 & $-0.734 \pm \mathrm{j} 3.98$ & 0.644 & 18.1 & All G \\
\hline & M 4 & $-0.642 \pm \mathrm{j} 0.56$ & 0.136 & 75.4 & WG \& G \\
\hline \multirow{4}{*}{$\begin{array}{l}480 \mathrm{M} \text { normal } \\
\text { power }\end{array}$} & M 1 & $-2.676 \pm j 8.48$ & 1.42 & 30.1 & G1, G2 \\
\hline & M 2 & $-2.869 \pm \mathrm{j} 8.93$ & 1.49 & 30.6 & G3, G4 \\
\hline & M3 & $-0.723 \pm \mathrm{j} 3.93$ & 0.636 & 18.1 & All G \\
\hline & M 4 & $-0.637 \pm \mathrm{j} 0.65$ & 0.145 & 70.0 & WG \& G \\
\hline \multirow{4}{*}{$\begin{array}{l}580 \text { M heavy } \\
\text { power }\end{array}$} & M 1 & $-2.683 \pm j 8.43$ & 1.41 & 30.3 & G1, G2 \\
\hline & M 2 & $-2.890 \pm \mathrm{j} 8.83$ & 1.48 & 31.1 & G3, G4 \\
\hline & M3 & $-0.700 \pm j 3.82$ & 0.618 & 18.0 & All G \\
\hline & M 4 & $-0.684 \pm j 0.74$ & 0.160 & 67.9 & WG \& G \\
\hline
\end{tabular}

\subsection{Eigenvalue Analysis with Simultaneous Coordinated PSSs, SVC POD and DFIG POD}

As aforementioned, the simultaneous coordinated PSSs and wide-area PODs are implemented in the two-area test system by the proposed design strategy. The wide-area feedback signal of SVC is selected as former subsections according to the indicator of $C O B I$. The COBI results with respect to DFIG of all lines' active powers for two inter-area oscillation modes are depicted in Figure 9. We can find that the active power in line 5-6 has the highest modal observability of critical inter-area oscillation modes M3. Thus, the active power in line 5-6 is considered as the most effective wide-area feedback input signal for DFIG POD.

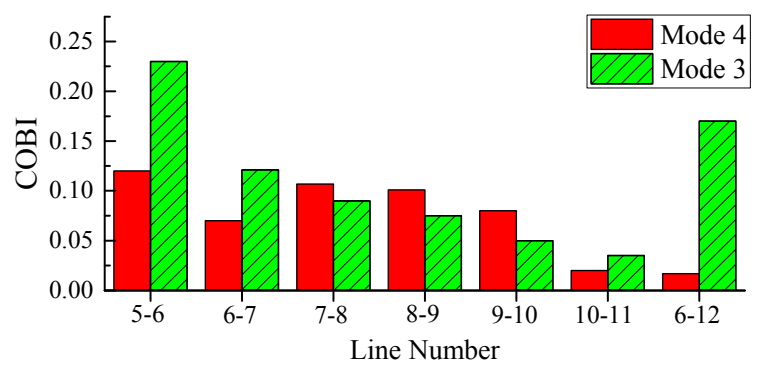

Figure 9. COBI of line active power as the input feedback signal of DFIG POD.

The dimension is 12 for two PSSs and two PODs. The controller parameters of coordinated PSSs and wide-area PODs are optimally tuned under three operating conditions as given in Table 5 . And Table 6 shows the modal analysis eigenvalue results of all three operating conditions. It can be seen from Table 6 that all of the four low frequency oscillation modes' damping ratios are greatly enhanced in comparison to that with no PSS and POD. What is more, the damping ratio of critical inter-area oscillation mode M3 are further improved in comparison to former two damping control strategies as discuss in Sections 4.3 and 4.4. Therefore, according to above analysis results, we concluded that the coordinated parameters design of multiple damping controllers can achieve better damping performance.

Table 5. Optimized parameters of PSSs and PODs.

\begin{tabular}{cccc}
\hline Stabilizer & $\boldsymbol{K}$ & $\boldsymbol{T}_{\mathbf{1}}, \boldsymbol{T}_{\mathbf{3}}$ & $\boldsymbol{T}_{\mathbf{2}}, \boldsymbol{T}_{\mathbf{4}}$ \\
\hline PSS1 & 16.7 & 0.995 & 0.050 \\
PSS3 & 28.9 & 0.771 & 0.038 \\
SVC POD & 10.4 & 0.217 & 0.046 \\
DFIG POD & 13.6 & 0.749 & 0.055 \\
\hline
\end{tabular}


Table 6. The oscillation modes with PSSs and PODs.

\begin{tabular}{|c|c|c|c|c|c|}
\hline Case & Modes & Eigenvalue & Frequency $(\mathrm{Hz})$ & Damping & Participation Generator \\
\hline \multirow{4}{*}{$\begin{array}{l}380 \mathrm{M} \text { light } \\
\text { power }\end{array}$} & M1 & $-2.434 \pm j 8.50$ & 1.41 & 27.5 & G1, G2 \\
\hline & M 2 & $-2.885 \pm j 9.04$ & 1.51 & 30.4 & G3, G4 \\
\hline & M3 & $-1.08 \pm \mathrm{j} 3.79$ & 0.627 & 27.4 & All G \\
\hline & M 4 & $-0.417 \pm \mathrm{j} 0.87$ & 0.154 & 43.2 & WG \& G \\
\hline \multirow{4}{*}{$\begin{array}{l}480 \text { M normal } \\
\text { power }\end{array}$} & M 1 & $-2.424 \pm j 8.47$ & 1.40 & 27.5 & G1, G2 \\
\hline & M 2 & $-2.888 \pm j 8.96$ & 1.50 & 30.7 & G3, G4 \\
\hline & M3 & $-1.100 \pm \mathrm{j} 3.71$ & 0.616 & 28.4 & All G \\
\hline & M 4 & $-0.473 \pm \mathrm{j} 0.88$ & 0.159 & 47.4 & WG \& G \\
\hline \multirow{4}{*}{$\begin{array}{l}580 \mathrm{M} \text { heavy } \\
\text { power }\end{array}$} & M 1 & $-2.451 \pm j 8.46$ & 1.40 & 27.8 & G1, G2 \\
\hline & M 2 & $-2.891 \pm \mathrm{j} 8.82$ & 1.48 & 31.2 & G3, G4 \\
\hline & M3 & $-0.827 \pm \mathrm{j} 3.81$ & 0.620 & 21.2 & All G \\
\hline & M 4 & $-0.667 \pm j 0.96$ & 0.186 & 57.1 & WG \& G \\
\hline
\end{tabular}

\subsection{Nonlinear Time-Domain Simulation}

To further verify the damping performance of the proposed coordinated design strategy in this paper, nonlinear time-domain simulations under the above four damping controller situations and three operating conditions are carried out by PSAT. A 3-phase fault is applied to the two-area test system at bus 7. It is assumed that the fault duration is six cycles $(100 \mathrm{~ms})$ and the fault is cleared without any topology change. In all the three operating conditions, the loads are regarded as PQ type.

The power angle differences of generators G1, G2 and G4 with respect to generator G3 under light, normal and heavy conditions are described in Figures 10-12, respectively. From these figures, the relative power angle low frequency oscillations can be damped out more or less by all of the three damping controller strategies. The simultaneous coordinated damping control design strategy achieves the satisfying damping effect with three power flow scenarios under consideration. The oscillations of disturbance dynamic response are effectively restrained in a very short time. Time domain simulation results are in accord with the previous eigenvalue analysis. Furthermore, the proposed coordinated design strategy is robust under all of the three operating conditions.

It is noteworthy that no much difference exists between the "PSS SVCPOD" and "PSS SVCPOD DFIGPOD" cases. That's because the whole system dynamic response is determined by the combined action of multiple controllers, such as AVR, PSS, and POD, and the damping effect of DFIG POD may not be obviously reflected in the disturbance response. Moreover, the system is already a relatively strong damping under the action of PSS SVCPOD, as shown in Table 4.

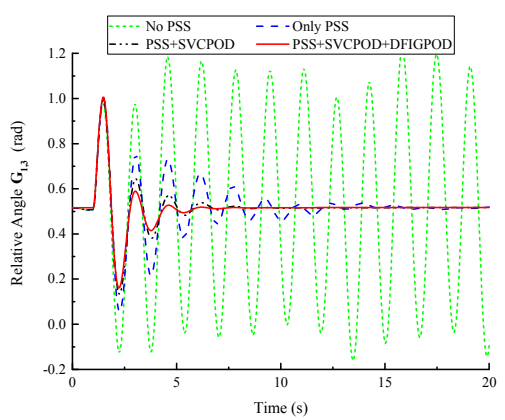

(a)

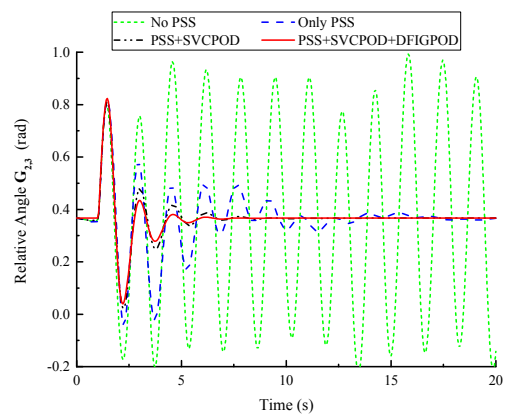

(b)

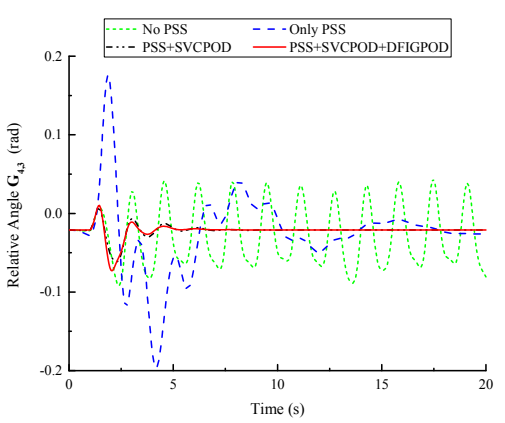

(c)

Figure 10. System bus 7 3-phase fault responses under light inter-area power flow transmission condition. (a) Relative power angle of generator G1 and G3; (b) Relative power angle of generator G2 and G3; and (c) Relative power angle of generator G4 and G3. 


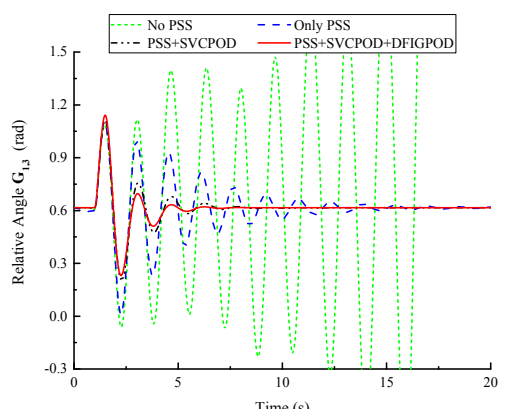

(a)

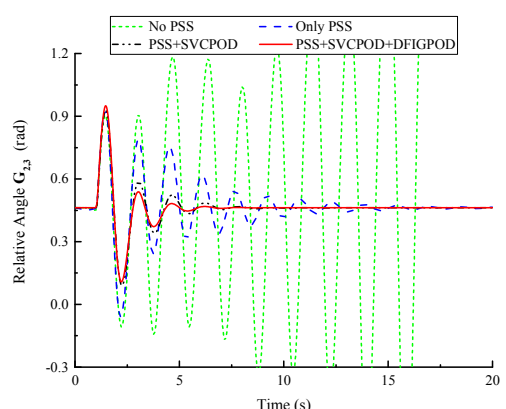

(b)

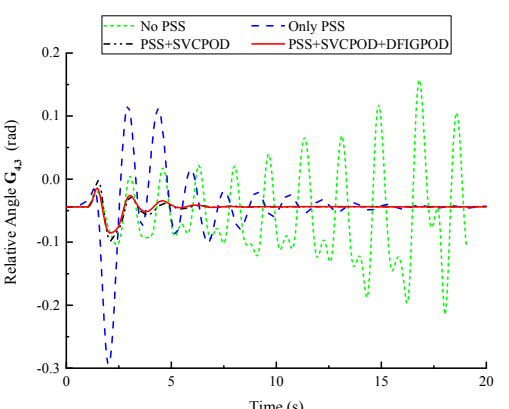

(c)

Figure 11. System bus 7 3-phase fault responses under normal inter-area power flow transmission condition. (a) Relative power angle of generator G1 and G3; (b) Relative power angle of generator G2 and G3; and (c) Relative power angle of generator G4 and G3.

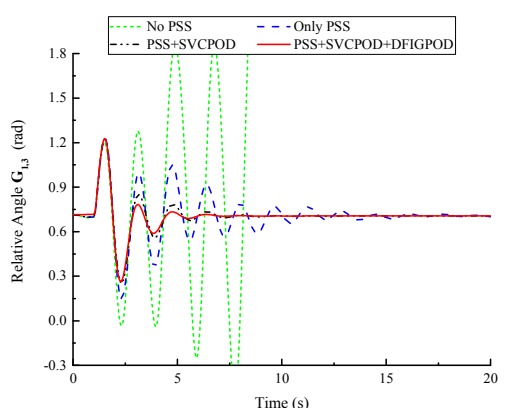

(a)

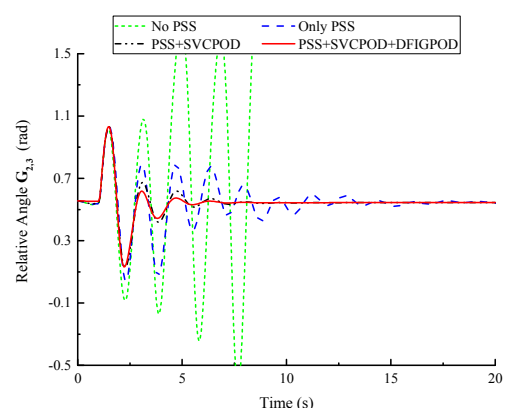

(b)

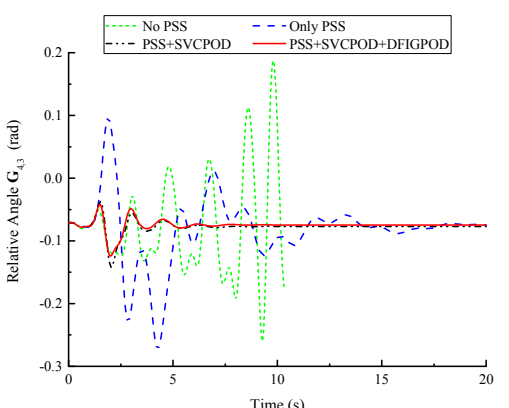

(c)

Figure 12. System bus 7 3-phase fault responses under heavy inter-area power flow transmission condition. (a) Relative power angle of generator G1 and G3; (b) Relative power angle of generator G2 and G3; and (c) Relative power angle of generator G4 and G3.

\subsection{Robustness Analysis}

To further evaluate the robustness of the proposed coordinated design strategy of multiple damping controllers, line outage or power flow reversing scenarios are considered in this two-area test system. The fault is the same as that in the previous simulation. Three scenarios are:

(1) Line 7-8 outage;

(2) Line 8-9 outage;

(3) The tie-line 7-9 active power is about $-310 \mathrm{MW}$.

The relative power angle with respect to three system operating scenarios are given in Figure 13. It can be seen from the relative power angle oscillation curves that the proposed coordinated multiple damping controllers design strategy has much better dynamic performance than other damping control strategies under the scenario 1 and 2. However, the system is unstable when the tie-line power flow orientations change, just like scenario 3. That's because the input signal of SVC POD is from the active power of tie-line 8-9. When the tie-line power flow reverses, the sign of the input signal is changed, and the system damping will degenerate greatly and even become negative. Therefore, the coordinated control strategy is robust under most kinds of power flow operating conditions and topological changes. But, it may become invalid if the system undergoes some thorough change, for example, power flow reversal of tie lines, as demonstrated in Figure 13c. Under such a circumstance, online adaptive coordination design [42-44] should be adopted to recover the validness of the strategy. 


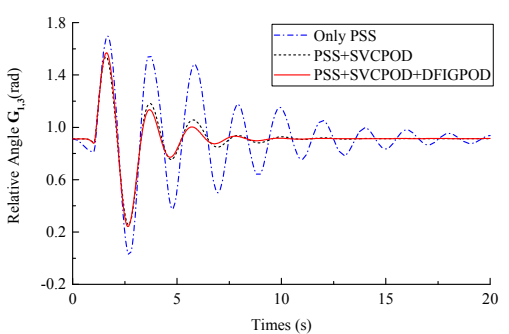

(a)

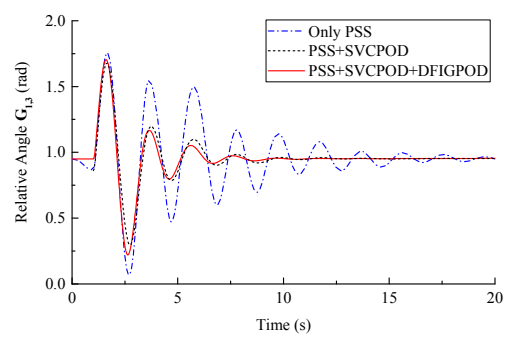

(b)

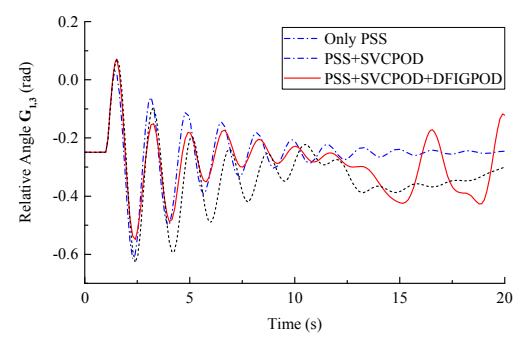

(c)

Figure 13. System bus 7 3-phase fault responses under different system operating scenarios.

(a) Line 7-8 outage; (b) Line 8-9 outage; and (c) Tie-line active power is $-310 \mathrm{MW}$.

When the operation mode of the studied system is changed greatly, the POD controllers' parameter values are switched to other sets of values, which are optimized off-line and matched with the considered operating condition. Based on this "off-line parameters optimization and on-line real-time matching" mechanism, the coordinated control strategy is more robust and the system has strong stability under various operating conditions.

\section{Case Study of New England Test System}

\subsection{Study System}

To investigate the applicability and scalability of the presented design strategy in coordinating multiple damping controllers in a much larger power system, IEEE 39 bus New England test system depicted in Figure 14 is considered in this study. To clarify the optimization design procedure, some modifications have been made in this system. For instance, three aggregated wind farms of which each has a capacity of 200 MVA are connected to the system at bus 14,16 and 17, respectively. Two SVCs with the capacity of 200 MVar are placed at bus 8 and 20 to improve the system voltage stability.

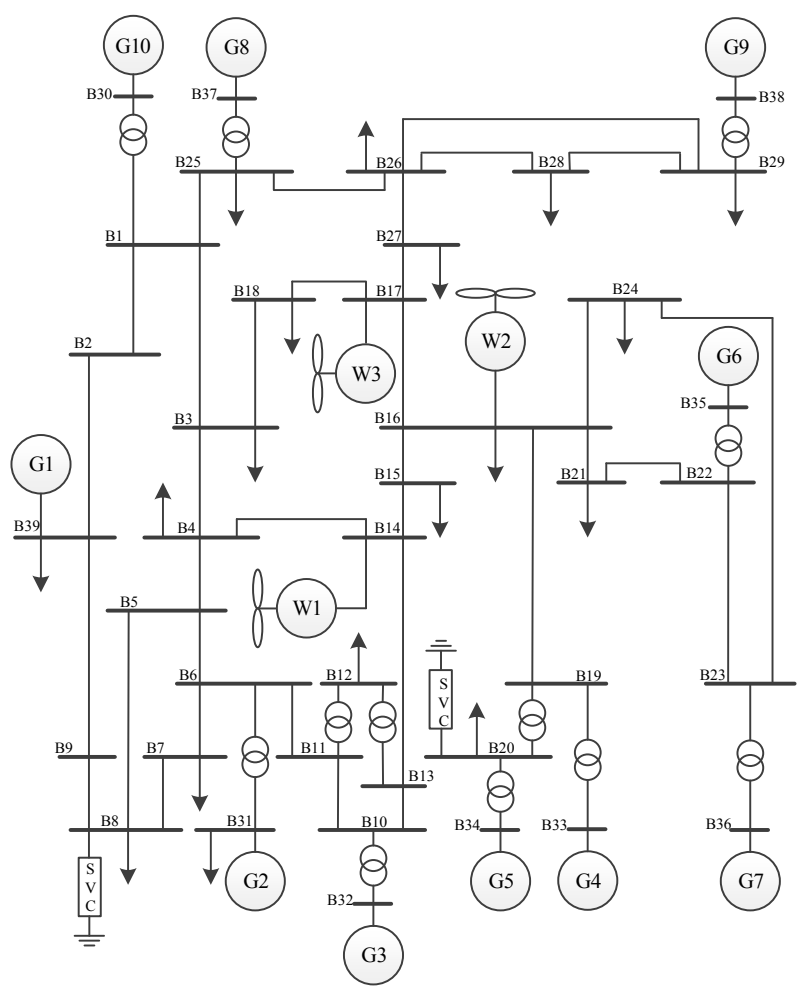

Figure 14. Modified IEEE 39 bus New England test system. 
In addition to normal operating condition, two other operating conditions corresponding to line 14-15 and line 21-22 outage are considered during the damping controller parameters optimization procedure.

\subsection{The Selection of Wide-Area Feedback Signals for PODs}

The modal analysis eigenvalue results in Table 7 reveal that the modified New England test system is unstable when there is no damping controller equipped. The three lowest frequency oscillation modes are negative damping (Modes 7, 8 and 9 are in bold font in the table), so a damping controller should be installed to the system. The most suitable wide-area feedback signals of PODs are determined by $C O B I$ index outlined in Section 3.1. And the final results are as following. The most appropriate feedback signals for the two SVC PODs are the active power in line 3-18 and line 17-27, while those for the three DFIG PODs are the active power in line 1-2, line 9-39, and line 9-39, respectively. These wide-area feedback signals are assumed to be measured by multiple dispersed PMUs and transmitted via WAMS.

Table 7. The oscillation modes without and with damping controllers.

\begin{tabular}{|c|c|c|c|c|}
\hline Case & Modes & Eigenvalue & Frequency (Hz) & Damping \\
\hline \multirow{9}{*}{ No PSS and POD controllers } & M 1 & $-3.15 \pm j 9.77$ & 1.63 & 30.7 \\
\hline & M 2 & $-0.38 \pm j 9.52$ & 1.52 & 3.99 \\
\hline & M 3 & $-0.53 \pm j 9.37$ & 1.49 & 5.65 \\
\hline & M 4 & $-0.45 \pm j 8.45$ & 1.35 & 5.26 \\
\hline & M 5 & $-0.15 \pm j 7.98$ & 1.27 & 1.91 \\
\hline & M 6 & $-0.23 \pm j 7.54$ & 1.20 & 3.00 \\
\hline & M 7 & $0.006 \pm \mathrm{j} 6.83$ & 1.09 & -0.0008 \\
\hline & M 8 & $0.36 \pm \mathrm{j} 6.24$ & 0.99 & -5.70 \\
\hline & M 9 & $0.15 \pm \mathrm{j} 4.07$ & 0.65 & -3.60 \\
\hline \multirow{9}{*}{$\begin{array}{l}\text { Uncoordinated PSS and } \\
\text { POD controllers }\end{array}$} & M 1 & $-2.53 \pm j 10.2$ & 1.67 & 24.1 \\
\hline & M 2 & $-2.56 \pm j 8.49$ & 1.41 & 28.8 \\
\hline & M 3 & $-0.76 \pm \mathrm{j} 8.10$ & 1.29 & 9.34 \\
\hline & M 4 & $-0.55 \pm \mathrm{j} 7.55$ & 1.20 & 7.27 \\
\hline & M 5 & $-1.22 \pm \mathrm{j} 6.86$ & 1.11 & $\mathbf{1 7 . 5}$ \\
\hline & M 6 & $-1.21 \pm j 5.00$ & 0.82 & 23.5 \\
\hline & M 7 & $-1.89 \pm j 3.85$ & 0.68 & 44.1 \\
\hline & M 8 & $-1.07 \pm j 3.48$ & 0.58 & 29.3 \\
\hline & M 9 & $-0.79 \pm \mathrm{j} 3.20$ & 0.52 & 24.0 \\
\hline \multirow{9}{*}{$\begin{array}{l}\text { Coordinated PSS and } \\
\text { POD controllers }\end{array}$} & M 1 & $-2.21 \pm \mathrm{j} 10.8$ & 1.75 & 20.1 \\
\hline & M 2 & $-2.98 \pm j 8.97$ & 1.50 & 31.5 \\
\hline & M 3 & $-1.68 \pm \mathrm{j} 8.22$ & 1.34 & 20.0 \\
\hline & M 4 & $-1.59 \pm j 7.64$ & 1.24 & 20.4 \\
\hline & M 5 & $-2.01 \pm \mathrm{j} 6.24$ & 1.04 & 30.7 \\
\hline & M 6 & $-1.23 \pm \mathrm{j} 4.86$ & 0.80 & 24.5 \\
\hline & M 7 & $-1.71 \pm j 3.90$ & 0.68 & 40.2 \\
\hline & M 8 & $-1.10 \pm j 3.45$ & 0.58 & 30.4 \\
\hline & M9 & $-0.68 \pm j 3.02$ & 0.49 & 21.9 \\
\hline
\end{tabular}

\subsection{Eigenvalue Analysis with Uncoordinated and Coordinated PSSs and wide-area PODs}

Firstly, the stabilizer gains and time constants of PSSs and PODs are calculated by the residue-based phase compensation theory at system normal operating condition without considering the coordination. The controller parameter results are shown in Table 8. Eigenvalue analysis results in Table 7 indicate that the modified New England test system with the uncoordinated PSSs and PODs has 9 electromechanical oscillation modes. And the frequency range of the oscillation modes is from about $0.5 \mathrm{~Hz}$ to $1.7 \mathrm{~Hz}$. It is obviously shown in Table 7 that three electromechanical oscillation modes 
do not meet the expected damping criterion (the damping ratios of Modes 3, 4 and 5 is less than 20\%), hence the controller parameters of PSSs and PODs need to be redesigned.

Table 8. Optimized parameters of PSSs and PODs.

\begin{tabular}{ccccccc}
\hline \multirow{2}{*}{ Stabilizer } & \multicolumn{3}{c}{ Residue-Based Method } & \multicolumn{3}{c}{ Proposed Method } \\
\cline { 2 - 7 } & $\boldsymbol{K}$ & $\boldsymbol{T}_{\mathbf{1}}, \boldsymbol{T}_{\mathbf{3}}$ & $\boldsymbol{T}_{\mathbf{2}}, \boldsymbol{T}_{\mathbf{4}}$ & $\boldsymbol{K}$ & $\boldsymbol{T}_{\mathbf{1}}, \boldsymbol{T}_{\mathbf{3}}$ & $\boldsymbol{T}_{\mathbf{1}}, \boldsymbol{T}_{\mathbf{3}}$ \\
\hline PSS1 & 20.2 & 0.580 & 0.032 & 2.86 & 0.461 & 0.086 \\
PSS2 & 11.8 & 0.845 & 0.076 & 17.6 & 0.139 & 0.054 \\
PSS3 & 22.1 & 0.702 & 0.015 & 16.3 & 0.395 & 0.051 \\
PSS4 & 9.8 & 0.980 & 0.023 & 28.5 & 0.675 & 0.034 \\
PSS5 & 5.7 & 0.353 & 0.044 & 10.4 & 0.987 & 0.072 \\
PSS6 & 35.9 & 0.923 & 0.069 & 27.6 & 0.535 & 0.087 \\
PSS7 & 26.5 & 0.674 & 0.074 & 8.89 & 0.365 & 0.021 \\
PSS8 & 26.8 & 0.289 & 0.019 & 12.4 & 0.992 & 0.075 \\
PSS9 & 17.3 & 0.536 & 0.038 & 13.5 & 0.879 & 0.069 \\
\hline SVC1 POD & 5.6 & 0.237 & 0.023 & 1.34 & 0.413 & 0.020 \\
SVC2 POD & 9.6 & 0.112 & 0.096 & 7.87 & 0.463 & 0.089 \\
DFIG1 POD & 17.1 & 0.354 & 0.083 & 18.9 & 0.570 & 0.042 \\
DFIG2 POD & 5.9 & 0.935 & 0.055 & 13.6 & 0.764 & 0.086 \\
DFIG3 POD & 20.9 & 0.656 & 0.034 & 22.0 & 0.312 & 0.054 \\
\hline
\end{tabular}

Then, the simultaneous coordinated control presented in this paper is adopted to improve system damping performance. During the controller parameters optimization design process, the expected damping ratio $\zeta_{0}$ is set as $20 \%$. The selected bounds for stabilizer gains and time constants are the same as the previous example. The dimension of the optimization problem is 42 , corresponding to nine PSSs and five PODs. The simultaneous tuning of the PSSs and PODs is demonstrated by considering three operating conditions. The final optimal parameter results of the PSSs and PODs with optimum objective value $\boldsymbol{J}=0$ are listed in Table 8. Meanwhile, Figure 15 depicts the optimization iteration convergence curve of the optimum objective $J$. The fast convergence curve indicates that the GWO algorithm can search for the optimal results with high efficiency even when dealing with such a complex high-dimensional problem. In Table 7, it's also listed that the eigenvalue analysis results of the modified New England test system with the proposed coordinated multiple damping controllers. From the damping ratios shown in Table 7, and the final objective value $J=0$, it can be concluded that all of the electromechanical oscillation eigenvalues are shifted to the specified sector region in left half $s$-plane. In other words, it ensures that the damping ratios of electromechanical oscillation modes are larger than $20 \%$, which is better than the uncoordinated situation.

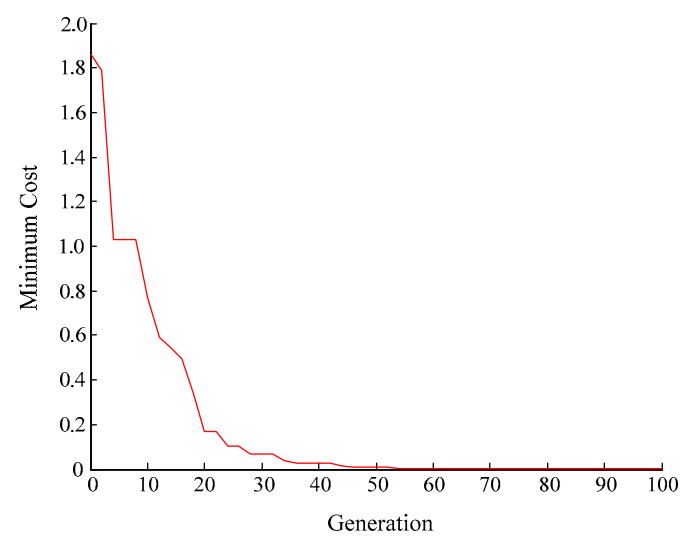

Figure 15. Optimum objective function convergence curve. 
It's worth noting that although the GWO algorithm is highly efficient, the eigenvalue calculation requires a lot of time in each fitness function evaluation. For a large system, the dimension of the optimization problem will increase greatly. Thus a more advanced algorithm, especially for high-dimensional problems, need to be developed.

\subsection{Nonlinear Time-Domain Simulation}

To confirm the superior damping performance of the proposed coordinated multiple damping controllers, nonlinear dynamic simulations are performed in the modified New England test system by PSAT. A 3-phase fault disturbance is applied to the system at bus 29, and the fault is cleared without any topology change after $100 \mathrm{~ms}$. The fault disturbance rejection performance and damping effect of the proposed coordinated multiple damping controllers control strategy are compared to those in the uncoordinated control situation. The relative power angle differences of all generators with respect to equilibrium generator G1 are depicted in Figure 16, whereby Figure 16a,b is the overall dynamic response under the action of coordinated and uncoordinated damping control strategy, and Figure $16 \mathrm{c}-\mathrm{f}$ is the detailed comparisons of some generators' relative power angles with different damping control strategies.

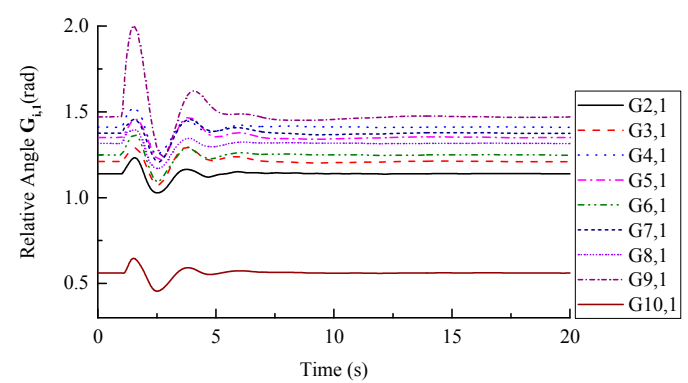

(a)

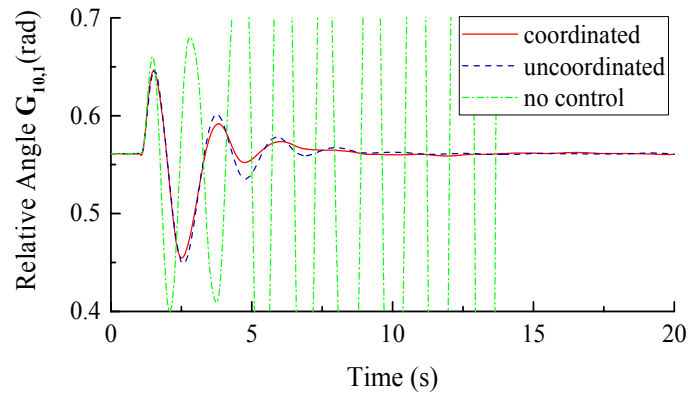

(c)

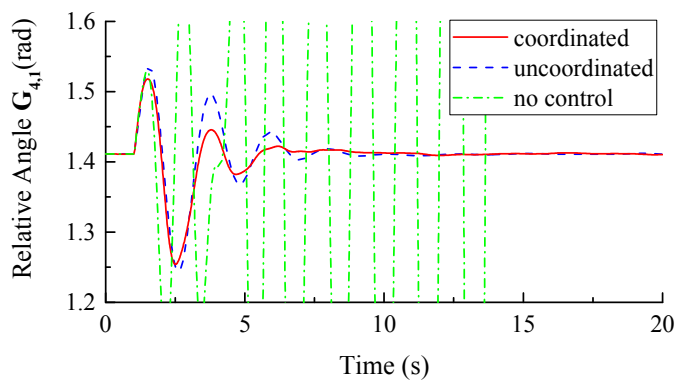

(e)

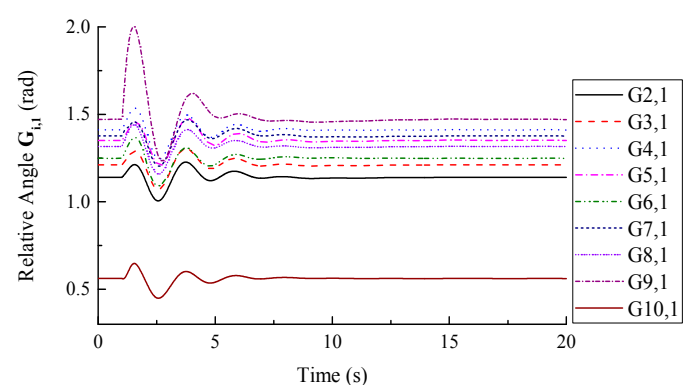

(b)

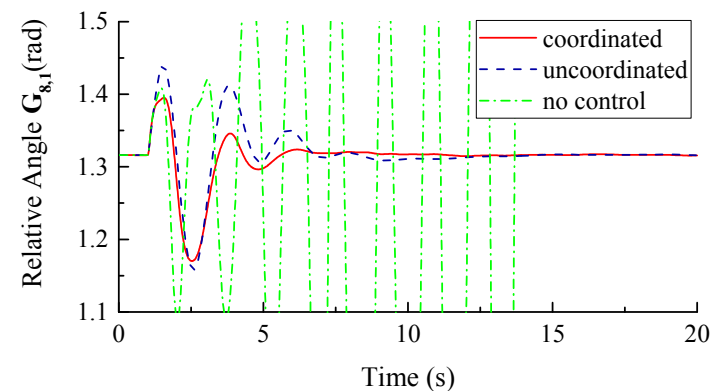

(d)

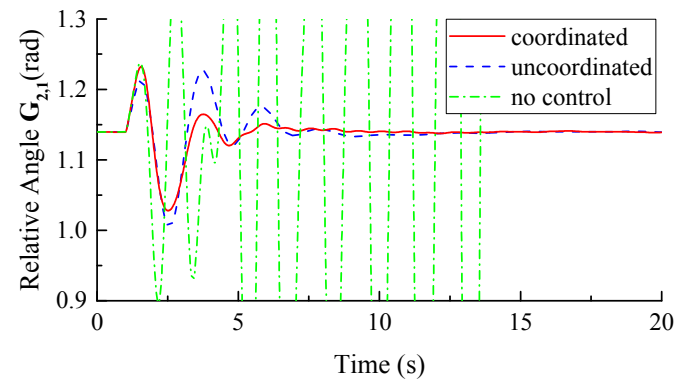

(f)

Figure 16. Relative power angle response of synchronous generators with different coordinated damping controllers. (a) Coordinated damping controllers; (b) Uncoordinated damping controllers; (c) $\mathrm{G}_{10,1}$ response under different control strategy; (d) $\mathrm{G}_{8,1}$ response under different control strategy; (e) $G_{4,1}$ response under different control strategy; and (f) $G_{2,1}$ response under different control strategy. 
The relative power angle oscillation curves shown in Figure 16 confirm that the system oscillations can be damped in a very short time by the proposed coordinated PSS and POD controllers. The relative power angle oscillation responses are quickly damped out. The disturbance response damping performance of the New England test system with the proposed coordinated multiple damping controllers is better than that of the system with uncoordinated PSS and POD controllers. The time-domain simulations are consistent with eigenvalue analysis results and demonstrate the scalability of the proposed coordinated design strategy.

\subsection{Robustness Analysis}

To further evaluate the robustness of the proposed coordinated design strategy of multiple PSSs and PODs damping controllers in the modified New England test system, a number of scenarios have been simulated. Only three of them are described here due to the space limitation:

(1) The power outputs of all three wind farms are decreased to $100 \mathrm{MW}$. The system is in the normal condition and subjected to a temporary fault at bus 15 with a duration of $100 \mathrm{~ms}$.

(2) The system loads increase by $10 \%$, and the fault is the same as aforesaid.

(3) Line 14-15 and Line 21-22 are out simultaneously, and the fault is the same as aforesaid.

The relative power angles of some generators with respect to G1 are shown in Figure 17. From these figures, it clearly indicates that the proposed coordinated design strategy can maintain the modified New England test system dynamic stability with an acceptable damping performance subjected to a short-circuit fault under a variety of operating conditions. The proposed coordinated controllers are more robust and effective than the uncoordinated controllers.

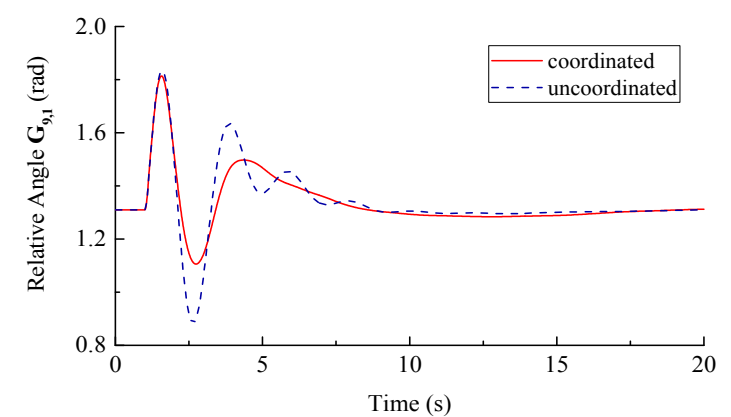

(a)

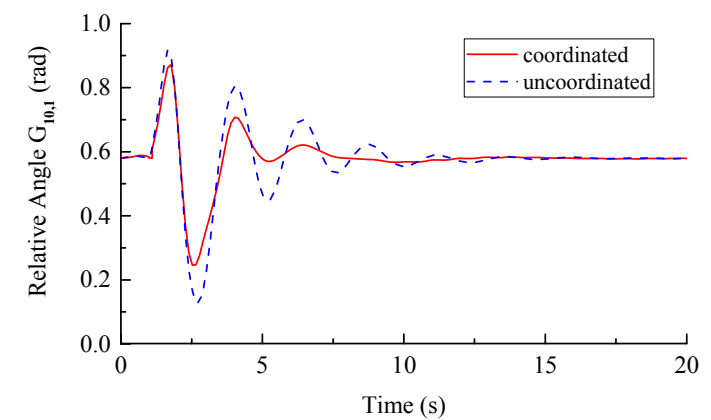

(b)

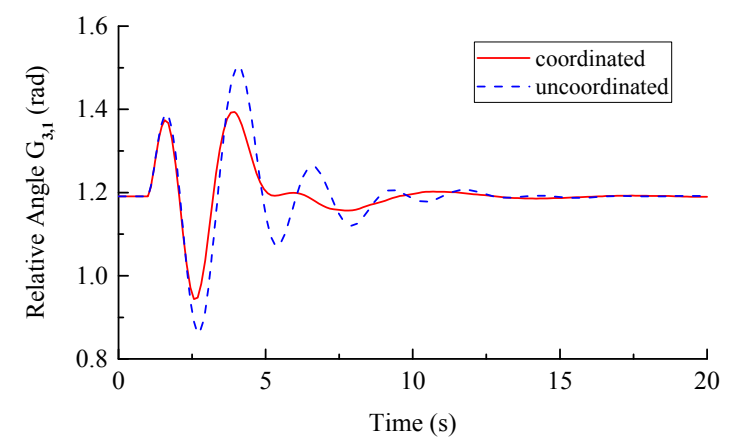

(c)

Figure 17. Relative power angle response of synchronous generators under different test scenarios (solid line: coordinated; dot line: uncoordinated). (a) Power outputs of wind farms are decreased to $100 \mathrm{MW}$; (b) Load increase 10\%; and (c) Line 14-15 and 21-22 outage.

\section{Conclusions}

This paper investigates the potential of coordinating multiple damping controllers, including PSS, SVC POD and DFIG POD, to damp out both local and inter-area low frequency oscillation 
modes in multimachine power systems. The parameter optimization of the fixed-structure lead-lag type PSS and POD is carried out simultaneously. Joint modal controllability/observability index is utilized to select the most appropriate wide-area feedback signals for PODs. To tune the optimal damping controller parameters, a GWO algorithm is employed to efficiently search for the eigenvalue-based parameter optimization solution. Frequency-domain eigenvalue analysis and nonlinear time-domain dynamic simulation studies in two classical modified benchmark test systems verify the feasibility and effectiveness of the proposed coordinated multiple damping controllers design strategy in stabilizing power system electromechanical oscillations. The simultaneous coordinated damping control design strategy is far superior to those with only one or two types of controllers or uncoordinated controllers. By implementing the proposed design strategy, the DFIG wind turbine equipped with POD can coordinate well with other damping controllers for contributing to power network damping performance.

It is worth noting that the coordinated multiple damping controller design strategy suggested in this paper can be easily expanded to the design of various kinds of multiple damping controllers. However, it may have some difficulty in obtaining the optimization solution within a reasonable time, when the size of the studied power system is extremely large. The parallel computing technologies and intelligent optimization algorithms which are suitable for solving high-dimensional problems need to be developed. How to apply this to design strategy for a large system is an ongoing work. Moreover, the volatility and uncertainty of wind power induced by ungovernable wind speed further increase the complexity of the simultaneous coordinated damping controller design. Future research will also be focused on extending the proposed design strategy to handle the robustness problem for the stochastic uncertainty of wind farm integrated power system.

Author Contributions: Jian Zuo and Yinhong Li conceived of and designed the simulations and the paper scope. Jian Zuo, Yinhong Li, and Dongyuan Shi performed the simulations, analyzed the data, discussed the results and wrote the manuscript. Xianzhong Duan suggested the research idea and reviewed the manuscript. All authors revised and approved the manuscript.

Conflicts of Interest: The authors declare no conflict of interest.

\section{References}

1. Rogers, G. Power System Oscillations; Kluwer Academic Publishers: New York, NY, USA, 2000.

2. Larsen, E.V.; Swann, D.A. Applying power system stabilizers part I: General concepts. IEEE Trans. Power Appar. Syst. 1981, PAS-100, 3017-3024. [CrossRef]

3. Kamwa, I.; Grondin, R.; Hebert, Y. Wide-area measurement based stabilizing control of large power systems-a decentralized/hierarchical approach. IEEE Trans. Power Syst. 2001, 16, 136-153. [CrossRef]

4. Zhang, X.P.; Rehtanz, C.; Pal, B. Flexible AC Transmission Systems: Modelling and Control; Springer: Heidelberg/Berlin, Germany, 2012.

5. Larsen, E.V.; Sanchez-Gasca, J.J.; Chow, J.H. Concepts for design of FACTS controllers to damp power swings. IEEE Trans. Power Syst. 1995, 10, 948-956. [CrossRef]

6. Majumder, R.; Pal, B.C.; Dufour, C.; Korba, P. Design and real-time implementation of robust FACTS controller for damping inter-area oscillation. IEEE Trans. Power Syst. 2006, 21, 809-816. [CrossRef]

7. Pal, B.; Chaudhuri, B. Robust Control in Power Systems; Springer: New York, NY, USA, 2005.

8. Cardenas, R.; Pena, R.; Alepuz, S.; Asher, G. Overview of Control Systems for the Operation of DFIGs in Wind Energy Applications. IEEE Trans. Ind. Electr. 2013, 60, 2776-2798. [CrossRef]

9. Laks, J.H.; Pao, L.Y.; Wright, A.D. Control of wind turbines: Past, present, and future. In Proceedings of the 2009 American Control Conference (ACC2009), St. Louis, MO, USA, 10-12 June 2009; pp. 2096-2103.

10. Liu, W.; Ge, R.; Lv, Q.; Li, H.; Ge, J. Research on a small signal stability region boundary model of the interconnected power system with large-scale wind power. Energies 2015, 8, 2312-2336. [CrossRef]

11. Vittal, E.; Keane, A. Identification of critical wind farm locations for improved stability and system planning. IEEE Trans. Power Syst. 2013, 28, 2950-2958. [CrossRef]

12. Ledesma, P.; Usaola, J. Doubly fed induction generator model for transient stability analysis. IEEE Trans. Energy Convers. 2005, 20, 388-397. [CrossRef] 
13. Waldner, M.; Erlich, I. Variable speed wind turbines based on electromechanical differential systems. IEEE Trans. Energy Convers. 2014, 29, 101-109. [CrossRef]

14. Morren, J.; De Haan, S.W.H.; Kling, W.L.; Ferreira, J.A. Wind turbines emulating inertia and supporting primary frequency control. IEEE Trans. Power Syst. 2006, 21, 433-434. [CrossRef]

15. Slootweg, J.G.; Kling, W.L. The impact of large scale wind power generation on power system oscillations. Electr. Power Syst. Res. 2003, 67, 9-20. [CrossRef]

16. Hughes, F.M.; Anaya-Lara, O.; Jenkins, N.; Strbac, G. A power system stabilizer for DFIG-based wind generation. IEEE Trans. Power Syst. 2006, 21, 763-772. [CrossRef]

17. He, P.; Wen, F.; Ledwich, G.; Xue, Y. An investigation on interarea mode oscillations of interconnected power systems with integrated wind farms. Int. J. Electr. Power Energy Syst. 2016, 78, 148-157. [CrossRef]

18. Tsourakis, G.; Nomikos, B.M.; Vournas, C.D. Contribution of doubly fed wind generators to oscillation damping. IEEE Trans. Energy Convers. 2009, 24, 783-791. [CrossRef]

19. Miao, Z.; Fan, L.; Osborn, D.; Yuvarajan, S. Control of DFIG-based wind generation to improve interarea oscillation damping. IEEE Trans. Energy Convers. 2009, 24, 415-422. [CrossRef]

20. Liu, Y.; Gracia, J.R.; King, T.J.; Liu, Y. Frequency regulation and oscillation damping contributions of variable-speed wind generators in the U.S. Eastern Interconnection (EI). IEEE Trans. Sustain. Energy 2015, 6, 951-958. [CrossRef]

21. Hagstrm, E.; Norheim, I.; Uhlen, K. Large-scale wind power integration in Norway and impact on damping in the Nordic grid. Wind Energy 2005, 8, 375-384. [CrossRef]

22. Alrifai, M.; Zribi, M.; Rayan, M. Feedback linearization controller for a wind energy power system. Energies 2016, 9, 771. [CrossRef]

23. Mishra, Y.; Mishra, S.; Tripathy, M.; Senroy, N.; Dong, Z.Y. Improving stability of a DFIG-based wind power system with tuned damping controller. IEEE Trans. Energy Convers. 2009, 24, 650-660. [CrossRef]

24. Singh, M.; Allen, A.J.; Muljadi, E.; Gevorgian, V.; Zhang, Y.; Santoso, S. Interarea oscillation damping controls for wind power plants. IEEE Trans. Sustain. Energy 2015, 6, 967-975. [CrossRef]

25. Hossain, M.J.; Pota, H.R.; Mahmud, M.A.; Ramos, R.A. Investigation of the impacts of large-scale wind power penetration on the angle and voltage stability of power systems. IEEE Syst. J. 2012, 6, 76-84. [CrossRef]

26. Kunjumuhammed, L.P.; Pal, B.C.; Oates, C.; Dyke, K.J. Electrical oscillations in wind farm systems: Analysis and insight based on detailed modeling. IEEE Trans. Sustain. Energy 2016, 7, 51-62. [CrossRef]

27. Domínguez-García, J.L.; Gomis-Bellmunt, O.; Bianchi, F.D.; Sumper, A. Power oscillation damping supported by wind power: A review. Renew. Sustain. Energy Rev. 2012, 16, 4994-5006. [CrossRef]

28. Leon, A.E.; Mauricio, J.M.; Gomez-Exposito, A.; Solsona, J.A. Hierarchical wide-area control of power systems including wind farms and FACTS for short-term frequency regulation. IEEE Trans. Power Syst. 2012, 27, 2084-2092. [CrossRef]

29. Li, Y.; Liu, F.; Cao, Y. Sequential design and global optimization of local power system stabilizer and wide-area HVDC stabilizing controller. J. Mod. Power Syst. Clean Energy 2016, 4, 292-299. [CrossRef]

30. Tan, A.; Lin, X.; Sun, J.; Lyu, R.; Li, Z.; Peng, L.; Khalid, M.S. A novel DFIG damping control for power system with high wind power penetration. Energies 2016, 9, 521. [CrossRef]

31. Surinkaew, T.; Ngamroo, I. Coordinated robust control of DFIG wind turbine and PSS for stabilization of power oscillations considering system uncertainties. IEEE Trans. Sustain. Energy 2014, 5, 823-833. [CrossRef]

32. Padhy, B.P.; Srivastava, S.C.; Verma, N.K. Robust wide-area TS fuzzy output feedback controller for enhancement of stability in multimachine power system. IEEE Syst. J. 2012, 6, 426-435. [CrossRef]

33. Abido, M.A. Optimal design of power-system stabilizers using particle swarm optimization. IEEE Trans. Energy Convers. 2002, 17, 406-413. [CrossRef]

34. Kundur, P. Power System Stability and Control; McGraw-Hill: New York, NY, USA, 1994.

35. Milano, F. Documentation for PSAT Version 2.1.6. 2011. Available online: http://faraday1.ucd.ie/psat.html (accessed on 20 April 2017).

36. Heniche, A.; Karnwa, I. Control loops selection to damp inter-area oscillations of electrical networks. IEEE Trans. Power Syst. 2002, 17, 378-384. [CrossRef]

37. Heniche, A.; Kamwa, I. Assessment of two methods to select wide-area signals for power system damping control. IEEE Trans. Power Syst. 2008, 23, 572-581. [CrossRef]

38. Kunjumuhammed, L.P.; Pal, B.C. Selection of feedback signals for controlling dynamics in future power transmission networks. IEEE Trans. Smart Grid 2015, 6, 1493-1501. [CrossRef] 
39. Abdel-Magid, Y.L.; Abido, M.A.; Mantaway, A.H. Robust tuning of power system stabilizers in multimachine power systems. IEEE Trans. Power Syst. 2000, 15, 735-740. [CrossRef]

40. Mirjalili, S.; Mirjalili, S.M.; Lewis, A. Grey Wolf Optimizer. Adv. Eng. Softw. 2014, 69, 46-61. [CrossRef]

41. Milano, F. An open source power system analysis toolbox. IEEE Trans. Power Syst. 2005, 20, 1199-1206. [CrossRef]

42. Wang, T.; Pal, A.; Thorp, J.S.; Wang, Z.; Liu, J.; Yang, Y. Multi-polytope-based adaptive robust damping control in power systems using CART. IEEE Trans. Power Syst. 2015, 30, 2063-2072. [CrossRef]

43. Malhotra, U.; Gokaraju, R. An add-on self-tuning control system for a UPFC application. IEEE Trans. Ind. Electr. 2014, 61, 2378-2388. [CrossRef]

44. Ma, J.; Wang, T.; Wang, S.; Gao, X.; Zhu, X.; Wang, Z.; Thorp, J.S. Application of dual Youla parameterization based adaptive wide-area damping control for power system oscillations. IEEE Trans. Power Syst. 2014, 29, 1602-1610. [CrossRef]

(C) 2017 by the authors. Licensee MDPI, Basel, Switzerland. This article is an open access article distributed under the terms and conditions of the Creative Commons Attribution (CC BY) license (http:/ / creativecommons.org/licenses/by/4.0/). 